\title{
İgnimbiritlerdeki Kılcal Su Emme Özelliğinin Ahlat Selçuklu Mezar Taşlarının Bozunmasındaki Rolü
}

The Role of Capillary Water Absorption Characteristics of Ignimbrites on the Deterioration of Ahlat Seljuk Tombstones

\section{Mutluhan AKIN ${ }^{1}$, İsmail DİNÇER ${ }^{1}$, Ali ÖZVAN², Vural OYAN ${ }^{3}$, Mücip TAPAN ${ }^{4}$}

${ }^{1}$ Nevşehir Hacı Bektaş Veli Üniversitesi, Jeoloji Mühendisliği Bölümü, NEVŞEHİR

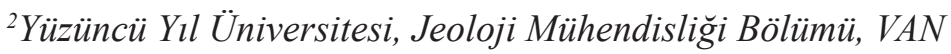

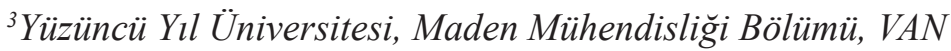

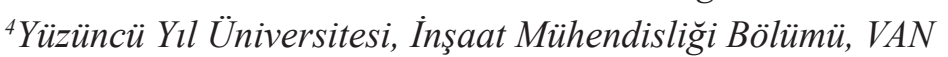

$\begin{array}{lll}\text { Geliş (received) } & : & 06 \text { Haziran (June) } 2016 \\ \text { Düzeltme (revised) } & : & 26 \text { Temmuz (July) } 2016 \\ \text { Kabul (accepted) } & : & 28 \text { Temmuz (July) } 2016\end{array}$

ÖZ

Selçuklular dönemine ait Ahlat Selçuklu mezar taşları, dünya üzerindeki bilinen en büyük Müslüman Mezarlığı olması ve taşıdığı tarihsel önem nedeniyle UNESCO’nun Dünya Kültür Mirası Geçici Listesi'nde yer almaktadır. Mezar taşı olarak, bölgede oldukça yaygın olarak bulunan ve piroklastik bir kaya türü olan ignimbiritler kullanılmış olup, yumuşak olmaları ve kolay işlenebilmelerini nedeni ile üzerlerine çeşitli motifler ve yazıtlar işlenmiştir. Ancak söz konusu mezar taşları, yaklaşık 800 yıllık süreç içerisinde bozunma etkilerine maruz kalmıştır. Mezar taşları incelendiğinde dikkati çeken en önemli unsur, birçok mezar taşının orta bölgelerine yakın kısımlarından kırılmış olmasıdır. Bu çalışma kapsamında Ahlat Selçuklu mezar taşlarının bozunmasına neden olan unsurların açığa çıkarılması amacıyla taze ignimbirit örnekleri üzerinde deneysel çalışmalar yapılmış ve özellikle kılcal su emmenin bozunma üzerindeki etkisi araştırılmıştır. Buna göre, ignimbiritlerin yüksek gözenekliliği ve kılcal su emme özelliği mezar taşlarının bozunmasındaki en önemli etkendir.

Anahtar Kelimeler: Ahlat Taşı, Bozunma, Ignimbirit, Kılcal Su Emme, Selçuklu.

\section{ABSTRACT}

The Seljuk Tombs of the Seljuk Empire in the Ahlat region are included in UNESCO's World Heritage Tentative List due to the fact that the tombstones are known to be the largest graveyards of Muslims with their historical significance. Tombstones were erected using ignimbrite type pyroclastic rocks which are widespread in the region, and several inscriptions and patterns were carved on them thanks to their 
Akın, Dinçer, Özvan, Oyan, Tapan

softness and easy processing. However, these tombstones have been subjected to weathering effects for almost a duration of 800 years. The most striking point after the inspection of tombstones is that many of them were broken from the middle section. In this study, experimental studies were carried out on fresh ignimbrite specimens and particularly the effect of capillary water absorption on deterioration was investigated to reveal the factors leading to deterioration of Ahlat Seljuk tombstones. Accordingly, high porosity and capillary water absorption characteristics of the ignimbrites are found to be the major reasons for the deterioration of tombstones.

Keywords: Ahlat Stone, Deterioration, Ignimbrite, Capillary Water Absorption, Seljuk.

\section{GÍRİŞ}

Kaya malzemeleri, doğal ve dayanıklı olmaları sebebiyle, geçmişten günümüze birçok yapıda ve tarihi eserde kullanılmıştır. Ancak, kaya kütlelerinde olduğu gibi, doğal yapıtaşları da atmosferik etkiler altında zamana bağlı olarak bozunma eğilimi göstermektedir. $\mathrm{Bu}$ nedenle doğal yapı malzemelerinin bozunma davranışlarının ortaya konması, uygulama ve yenileme (restorasyon) çalışmaları için oldukça önemlidir. Bu amaca paralel olarak son yıllarda yapıtaşı bozunmasına yönelik birçok bilimsel araştırma gerçekleştirilmiştir (Topal ve Doyuran, 1997; Siegesmund vd., 2002; Prikryl vd., 2003; Topal ve Sözmen, 2003; Öner vd., 2006; Török, 2006; Akın ve Özsan, 2011, Korkanç, 2013; Cardanes vd., 2014).

Piroklastik bir kaya türü olan ignimbirit, hafif ve kolay işlenebilir olmasından dolayı sıklıkla tercih edilen yapıtaşlarından biridir. Aynı zamanda yüksek 1sı ve ses yalıtım özelliğine sahip olan ignimbiritler, tarihi birçok yapıda kullanılmasının yanı sıra, günümüzde de yap1 sektöründe özellikle kaplama taşı olarak tercih edilmektedir. Van Gölü'nün batı sahilinde yer alan Ahlat ilçesi ve yakın çevresindeki tarihi eserlerde ve güncel yapılarda da ignimbiritler yoğun olarak kullanılmıştır. Selçuklular 1000'li yılların başlarında Ahlat yöresinde hüküm sürmeye başladıklarında, mimari eserlerinde kolay işlenebilir olmasından dolayı bölgede yaygın olarak bulunan ignimbiritleri kullanmışlardır. $\mathrm{Bu}$ eserlerin en önemlilerinden bir tanesi de bu çalışmanın ana konusunu oluşturan tarihi Ahlat Selçuklu Mezarları'dır (Şekil 1).

Yaklaşı $1700 \mathrm{~m}$ kotundaki düz bir arazi üzerinde yer alan ve ignimbirit kullanılarak yapılan bu mezar taşları, bölgenin sert iklim koşullarının da etkisiyle yaklaşık 800 yıldır bozunma etkilerine maruz kalmaktadır. 19502015 arasındaki meteorolojik gözlemlere göre, bölgenin kurak bir iklime sahip olduğu ve ortalama en düşük sıcaklık değerlerinin Aralık - Mart ayları arasında olduğu görülmektedir (Çizelge 1). Öte yandan, ilde gözlenen en düşük sıcaklık -22 $\mathrm{C}^{\circ}$ olarak Şubat, en yüksek sicaklık ise $38 \mathrm{C}^{\circ}$ olarak Temmuz ayında ölçülmüştür (www.mgm.gov.tr). Bölgedeki yüksek sicaklık farkları, özellikle atmosferik koşullara maruz kalan Selçuklu Mezar Taşları'nı etkileyen unsurların başında gelmektedir. 


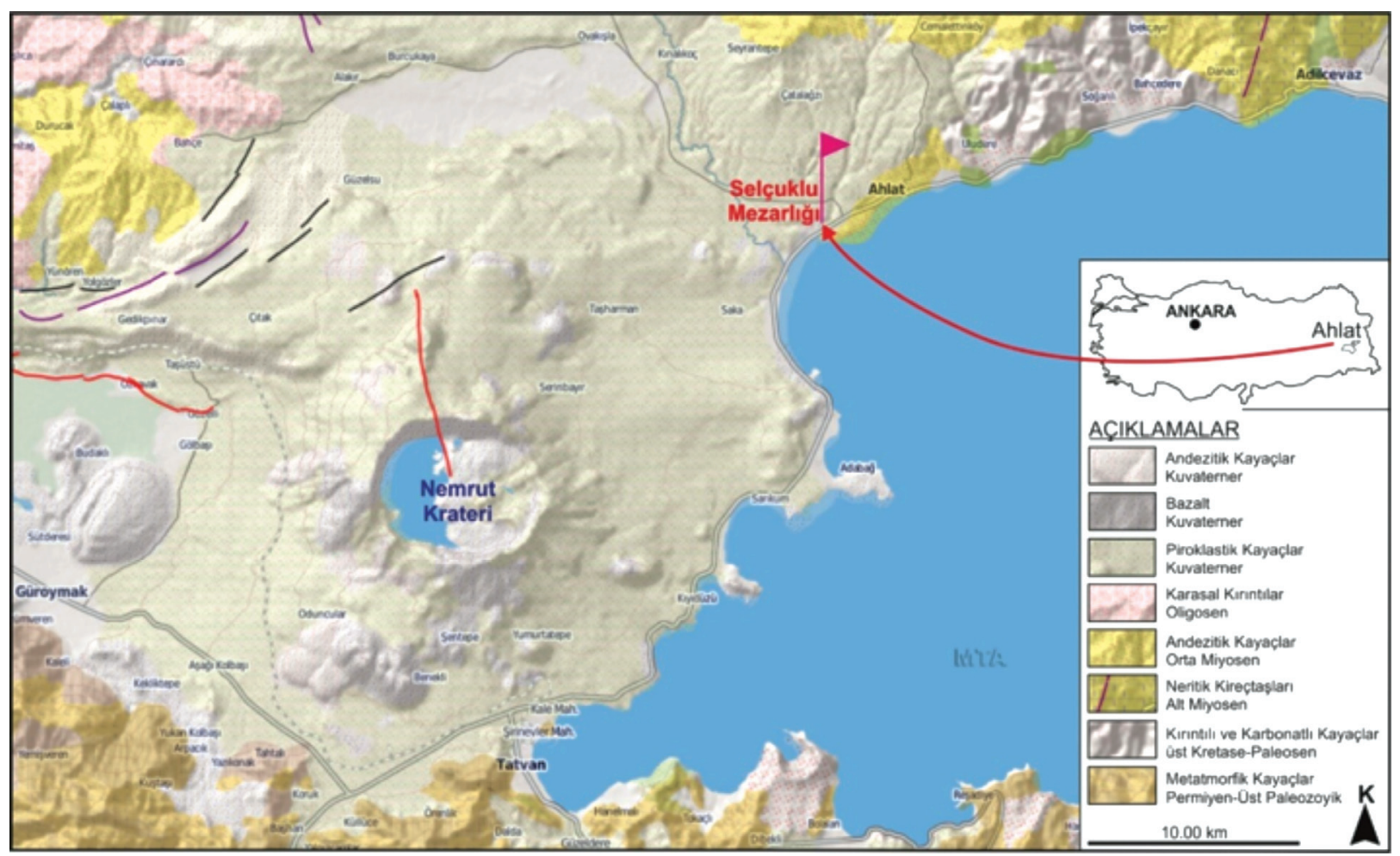

Şekil 1. Ahlat Selçuklu Mezarları yerbulduru ve jeoloji haritası (Akbaş vd., 2015'ten değiştirilerek).

Figure 1. Location and geological map of the Ahlat Seljuk Tombs (after Akbaş et al., 2015).

Bölgede kar yağış miktarı da yüksek olup, bugüne kadar ölçülen en yüksek kar yağış1, 1968 y1lında $343 \mathrm{~cm}$ olarak ölçülmüştür (www. mgm.gov.tr). Özellikle soğuk dönemlerde çevrimsel olarak etkili olan donma-çözülme, yöredeki yapıtaşlarının bozunmasındaki en önemli etkenlerden bir tanesidir (Özvan vd., 2015). Kimyasal ve fiziksel bozunma karşısında oldukça hassas olan bu ignimbiritler, Nemrut volkanizmasının ürünüdürler (Aydar vd., 2003; Karaoğlu vd., 2005; Özdemir vd., 2006). Kültürel miras olan Ahlat Selçuklu Mezar Taşları'nda bozunmanın izleri gözlenebilmektedir (Şekil 2). Özellikle Ahlat yerleşim merkezine daha yakın olan mezar taşlarında kuru iklim ve yüksek karbon içeriğine bağlı olarak liken oluşumları dikkati çekmektedir. Söz konusu likenler daha çok Selçuklu Mezar Taşları'nın üst bölgelerinde yer almaktadır. Literatürde likenlerin yapıtaşı bozunmasındaki rolü konusunda farklı görüşler bulunmaktadır. Liken oluşumları zaman içerisinde doğal yapıtaşlarının görünümü ve özellikleri üzerinde olumsuz etkiler yaratabilirler (Garty, 1992; Lisci vd., 2003). Öte yandan, diğer bazı araştırmacılar ise kaya yüzeyini kaplayan likenlerin kayayı fiziksel bozunmanın etkilerinden koruduğunu öne sürmektedir (Arino vd., 1995; Seaward, 2001; Mottershead vd., 2003; Garcia-Valles vd., 2003; Carter ve Viles, 2005). 
Akın, Dinçer, Özvan, Oyan, Tapan

Çizelge 1. Bitlis ili ve civarına ait uzun yıllar içinde gerçekleşen ortalama sıcaklık değerleri (1950 - 2015, www.mgm.gov.tr). Table 1. Average temperature values of the long-term period in Bitlis and close vicinity (1950-2015, www.mgm.gov.tr).

$$
\text { 峞 }
$$

\begin{tabular}{|c|c|c|c|c|c|c|c|c|c|c|c|c|}
\hline Sicaklık $\left({ }^{\circ} \mathbf{C}\right)$ & -3.0 & -2.1 & 1.7 & 7.6 & 13.2 & 18.5 & 22.8 & 22.4 & 17.6 & 11.3 & 4.7 & -0.9 \\
\hline
\end{tabular}

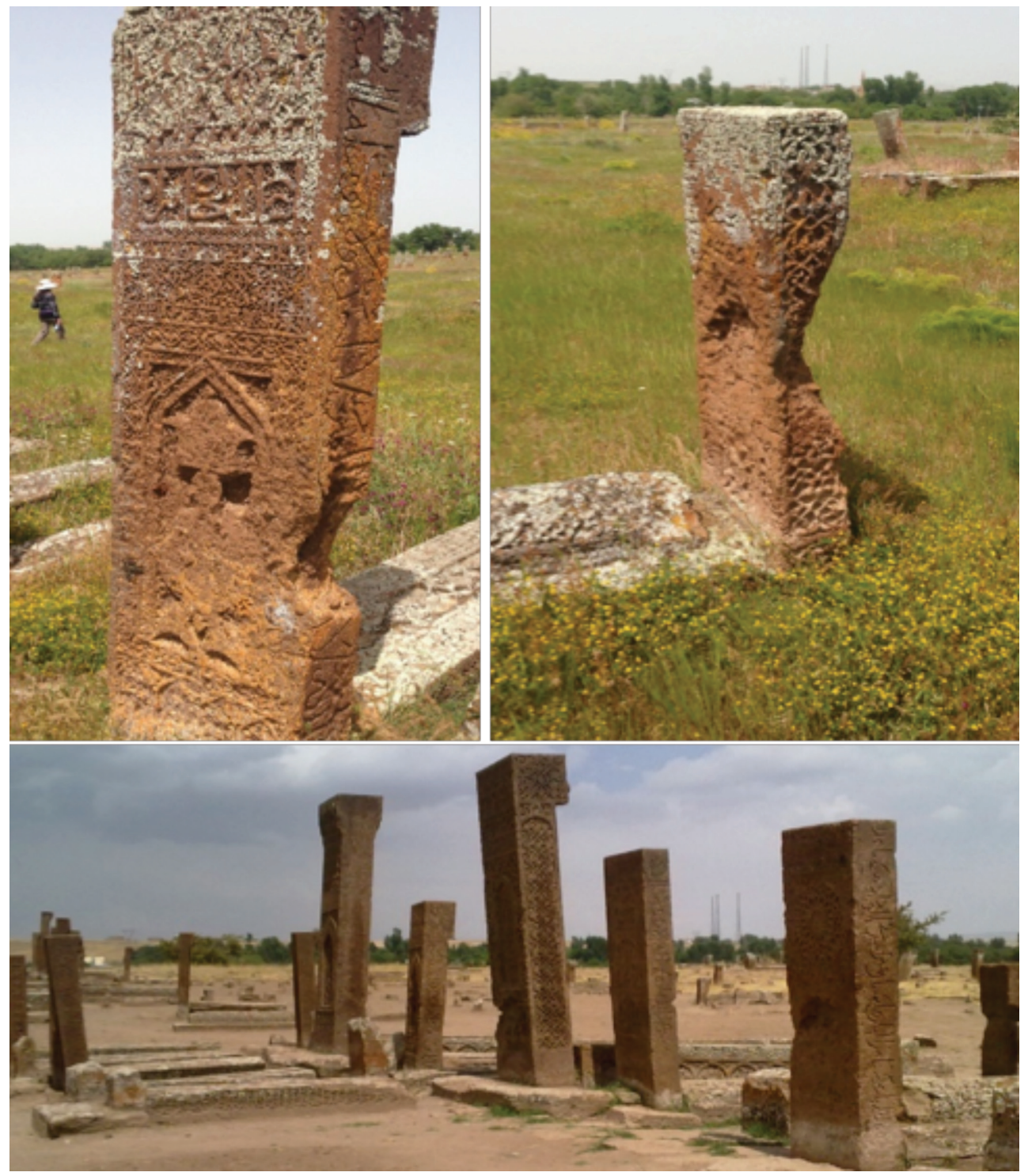

Şekil 2. Ahlat Selçuklu mezar taşlarından çeşitli görünümler.

Figure 2. Several views of the Ahlat Seljuk Tombstones. 
Fiziksel ve kimyasal etkiler nedeniyle bozunan bu tarihi mezar taşları üzerinde yapılan arazi incelemelerinde dikkati çeken en önemli problemler, mezar taşlarının yaklaşık orta noktalarından kırılması, renk değişimleri ve liken oluşumlarıdır (Özvan vd., 2015). Ancak, tüm bu olumsuz etkenlere karşın, mezar taşlarının birçoğunun üzerindeki yazıtlar korunmuş durumdadır. $\mathrm{Bu}$ çalışma, Ahlat Selçuklu Mezar Taşları'nın bozunmasında ve yaklaşık orta noktalarından kırılmasındaki nedenlerin araştırılması amacıyla gerçekleştirilmiştir. $\mathrm{Bu}$ kapsamda, ignimbiritlerin fiziko-mekanik özelliklerinin ortaya konması ve kılcal su emme (kapilarite) özelliğinin Ahlat Selçuklu Mezar Taşları'nın bozunması üzerindeki etkisinin araştırılması amacıyla arazi ve laboratuvar çalışmaları yapılmıştır. Arazide mezar taşlarının yakınındaki ignimbirit ocaklarından alınan blok örnekler laboratuvara nakledilerek karot örnekler alınmış ve deneysel çalışmalar bu örnekler üzerinde uygulanmıştır. Ayrıca ignimbiritlerdeki gözenek boyutları ve dağılımı civa porozimetresi deneyleri ile belirlenmiştir. Son olarak, ignimbiritlerdeki kılcal su emmenin bozunma üzerindeki etkisi bir model deney üzerinde incelenerek mezar taşlarında gözlenen bozunma modeli açıklanmaya çalışılmıştır.

\section{AHLAT SELÇUKLU MEZAR TAŞLARININ TARİHSEL ÖNEMİ}

Van Gölü'nün batı sahilinde kurulmuş olan ve Bitlis iline bağlı olan Ahlat ilçesi tarihi bir yerleşimdir. Nemrut ve Süphan volkanlarının ortasında kurulmuş olan Ahlat, Selçuklular'dan kalma birçok cami, hamam, kümbet ve mezar gibi tarihi yapı barındırmaktadır. Selçuklu Türkleri Ahlat'a 1093 y1lında gelmişler ve bu yörede 1230 yılına kadar hüküm sürmüşlerdir. Bölgedeki tarihi yapılar, Selçuklu mimarisinin en güzel eserleri arasında yer almaktadır. Tarihi Ahlat Selçuklu Mezarlığı, dünya üzerindeki en büyük Müslüman Mezarlığı olup (Karamağaralı, 1992), UNESCO'nun Dünya Kültür Miras1 Geçici Listesi'nde yer almaktadır. Üzerlerinde farklı desen, rölyef ve yazıtlar içeren Selçuklu Mezar Taşları farklı kalınlık ve genişliklerde olup, yaklaşık 1-2 m yüksekliktedir. Bu mezar taşlarından en yüksek olanı, toprağa gömülü olan kısmı dahil olmak üzere, 5 m'dir. Mezar taşlarının tamamı, yöresel olarak Ahlat Taşı olarak da adlandırılan ignimbirit kullanılarak yapılmıştır.

\section{İNCELEME ALANININ JEOLOJISİ}

Van Gölü'nün güneybatısında yer alan Kuvaterner yaşlı Nemrut stratovolkanı, Doğu Anadolu Bölgesi'ndeki kıta-kıta çarpışmasının bir ürünüdür (Keskin, 2007). Deniz seviyesinden yaklaşık 2950 m yüksekte olan bu volkanın taban alan1 $210 \mathrm{~km}^{2}$ 'dir ve 7x8 km'lik bir kaldera çapına sahiptir (Şekil 1). Karaoğlu vd. (2005) ve Özdemir vd. (2006) tarafından belirtildiği üzere, Nemrut volkanizması, kaldera öncesi, kaldera sonrası ve geç dönem olmak üzere üç ana safhaya ayrılmaktadır. Kaldera öncesi dönemdeki ilksel volkanizma malzemesini lav akıntıları, lav domları ve ignimbiritler gibi büyük miktarda piroklastik malzeme oluşturmaktadır. Kaldera sonrası dönem ise riyolitik lav akıntıları ve dayklar ile temsil edilmektedir. Geç dönem volkanizmasında ise vitrofirik, riyolitik ve bazaltik lav akıntıları bulunmaktadır. Nemrut volkanizmasının ürünü olan ignimbiritler kaldera öncesi dönemde patlama ürünü olarak yüzeye çıkmışlar ve Nemrut volkanının yamaçları 
Akın, Dinçer, Özvan, Oyan, Tapan

boyunca tüm yönlerde yayılmışlardır (Şekil 1). Bölgedeki ignimbiritlerin toplam hacmi $58 \mathrm{~km}^{3}$ civarındadır (Özdemir vd., 2006).

Bölgede yayılım gösteren ignimbiritler heterojen bir yap1 göstermekte olup, farklı oranlarda pomza, volkanik cam ve litik malzeme içerebilmektedirler. Piroklastik akma ürünü olan bu ignimbiritler, yer çekimi ve laminer akım sistemi içerisinde yüksek sıcaklık koşullarında oluşmuşlardır. Bu nedenle Ahlat bölgesinde farklı renk, doku ve yapısal özellik gösteren ve farklı kaynaklaşma derecelerine sahip ignimbiritler mevcuttur.

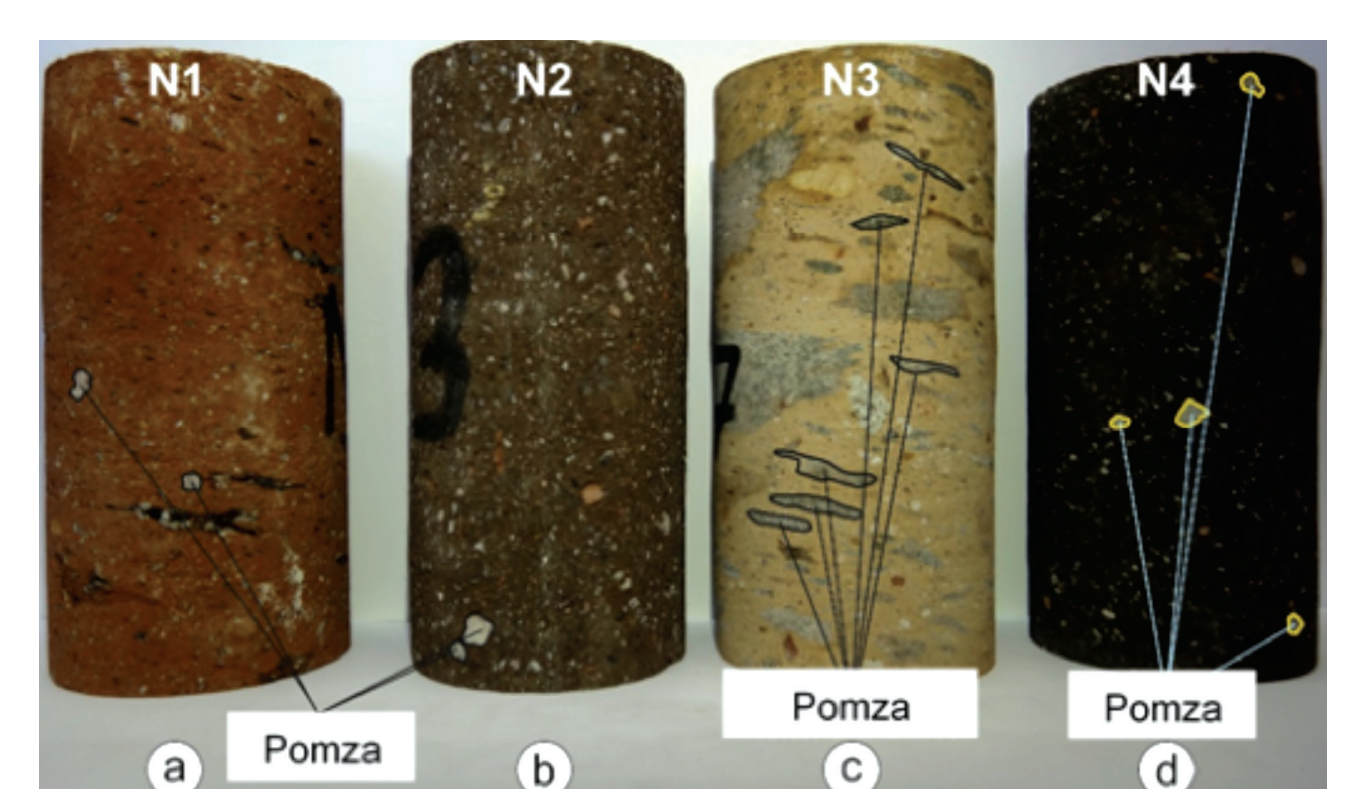

Taşları'nın yapımında kullanılmıştır. Bölgedeki ignimbirit oluşumları genel olarak masif ve hamur ağırlıklı bir yapı gösterseler de, zaman zaman farklı boyutlarda hamur içerisinde dağılmış pomza ve litik malzeme de gözlenmektedir. Ancak, genel olarak değerlendirildiğinde litik malzemeye oranla pomza parçacıkları hamur içerisinde daha çok bulunmaktadır. Nemrut ignimbiritlerinin kaynaklaşma dereceleri de iyiden kötüye kadar değişmektedir. Orta-iyi derecede kaynaklaşmış olan N3 ignimbiritleri sarımsı gri-krem renklidir ve diğer ignimbiritlere oranla daha iri ve fazla litik malzeme içermekle

Şekil 3. Çalışmada incelenen dört farklı ignimbirit örneğinden görünümler.

Figure 3. Close-up views of four different ignimbrite samples investigated in this study.

\section{MALZEME VE YÖNTEM}

Bu çalışmada, bölgedeki tarihi eserlerde ve yapılarda yaygın olarak kullanılan N1 (kırmızımsı kahverengi), N2 (koyu kahverengi), N3 (sarıms1 gri) ve N4 (siyah) olmak üzere dört farklı ignimbirit seviyesi değerlendirilmiştir (Şekil 3). Bu örneklerden N1 ve N2, Selçuklu Mezar birlikte pomza tanelerinde daha fazla yassılaşma gözlenmektedir. Oldukça koyu renkli olan N4 grubu ignimbiritler ise ignimbirit seviyeleri arasında en alt seviyede bulunmaktadır (Özvan vd., 2015).

Ahlat Selçuklu Mezarlığı yakınında bulunan ve tarihi mezar taşlarının yapımında 
da kullanıldığ 1 düşünülen ocaklardan yaklaşık $50 \times 50 \times 30 \mathrm{~cm}$ boyutlarında blok örnekler alınmıştır. Araziden laboratuvara nakledilen blok örneklerden boy/çap oranı en az 2/1 olan NX çaplı karot örnekler alınmıştır. Deneysel çalışmalar, UNE-EN 1925 (1999), ISRM (2007) ve TS699 (2009) standartları dikkate alınarak gerçekleştirilmiştir. $\mathrm{Bu}$ kapsamda ignimbirit örneklerinin birim hacim ağırlı̆̆1 $(\mathrm{g})$, görünür gözenekliliği (n), ağırlıkça su emme yüzdesi, P-dalgası hızı (Vp), tek eksenli basınç dayanımı ve kılcal su emme katsayısı (C) belirlenmiştir.

Bu çalışmada, Selçuklu Mezar Taşları'nda kullanılan ignimbiritlerin su emme potansiyelleri belirlenerek, k1lcal su emmenin mezar taşlarının bozunmasındaki rolü incelenmiştir. Örnekler üzerindeki k1lcal su emme deneyleri UNE-EN 1925 (1999) standartlarına göre gerçekleştirilmiştir. Buna göre, su derinliği $3.00 \pm 1 \mathrm{~mm}$ olan bir kabın içerisine 3 adet ignimbirit örneği (boy/çap oranı 1) dik olarak yerleştirilmiştir. $\mathrm{Su}$ seviyesinde buharlaşmaya bağlı olarak değişim olmaması için deney kabı yeterince büyük seçilmiştir. 24 saat su içinde bekletilen örnekler tarafindan emilen su belirli zaman aralıklarında $(3,5,10,15,30,60,480$ ve 1440 dakika) tartılarak ölçülmüştür. Kılcal su emme katsayısı (C) aşağıdaki formülle belirlenmiştir.

$$
\mathrm{w}=\mathrm{c} \cdot \mathrm{t}^{0.5}
$$

Formülde $\mathrm{w}$ emilen su miktarını $\left(\mathrm{gr} / \mathrm{m}^{2}\right), \mathrm{t}$ ise emilme zamanını (s) göstermektedir.

Ahlat Selçuklu Mezar Taşları, genellikle 1.5-2 m yükseklikte olmakla birlikte, en yüksek mezar taşı 5 m'dir (Elmastaş, 2001).
Laboratuvar ortamında gerçek boyutlu mezar taşlarının kullanımı mümkün olmadığından, mezar taşlarındaki kılcal su emme özelliğini incelemek amaciyla 1:10 ölçeğinde, 5 cm'lik kısmı toprak içine gömülü olacak şekilde ignimbirit malzemeden model mezar taşları yapılmıştır. Model olarak kullanılan örnekler, kılcal hareketi doğrudan etkilememek için litik malzeme yönlenmeleri düşeye yakın olacak şekilde toprağa yerleştirilmiştir. Model deney sırasında, mezar taşlarındaki kılcal su emmenin ve buna bağlı kılcal tuz hareketinin gözlenmesi için model mezar taşları haftada iki kez \%14'lük $\mathrm{MgSO}_{4}$ çözeltisi ile sulanmıştır.

\section{AHLAT İGNIMBIRITLERININ PETROG- RAFIKK VE JEOKİMYASAL ÖZELLİKLERİ}

Çalışma kapsamında incelenen ignimbirit örneklerinin ince kesit görüntüleri Şekil 4'te sunulmaktadır. Buna göre N1 nolu örnek içinde hornblend, sanidin, kayaç parçaları ve pomza kıymıkları; öteksitik hamur içinde dağılmış durumdadır (Şekil 4-a). İncelenen kesitlerde ortalama litik malzeme oranı N1 nolu örnek için \% 13 civarındadır. N2 nolu örnek içinde hornblend, plajiyoklaz ve sanidin kristlaleri ile birlikte pomza parçaları bulunmaktadır (Şekil 4-b). N2 nolu örnek için litik malzeme oranı ise \% 17'dir. N3 nolu örnek plajiyoklaz, sanidin ve pomza ile yoğun kayaç parçalarından oluşmaktadır (Şekil 4-c). Litik malzeme oranı \% 32 'dir. N4 nolu örnek içinde pomza parçaları ve sanidin kristalleri egemendir (Şekil 4-d) ve litik malzeme oran1 \% 20'dir. 

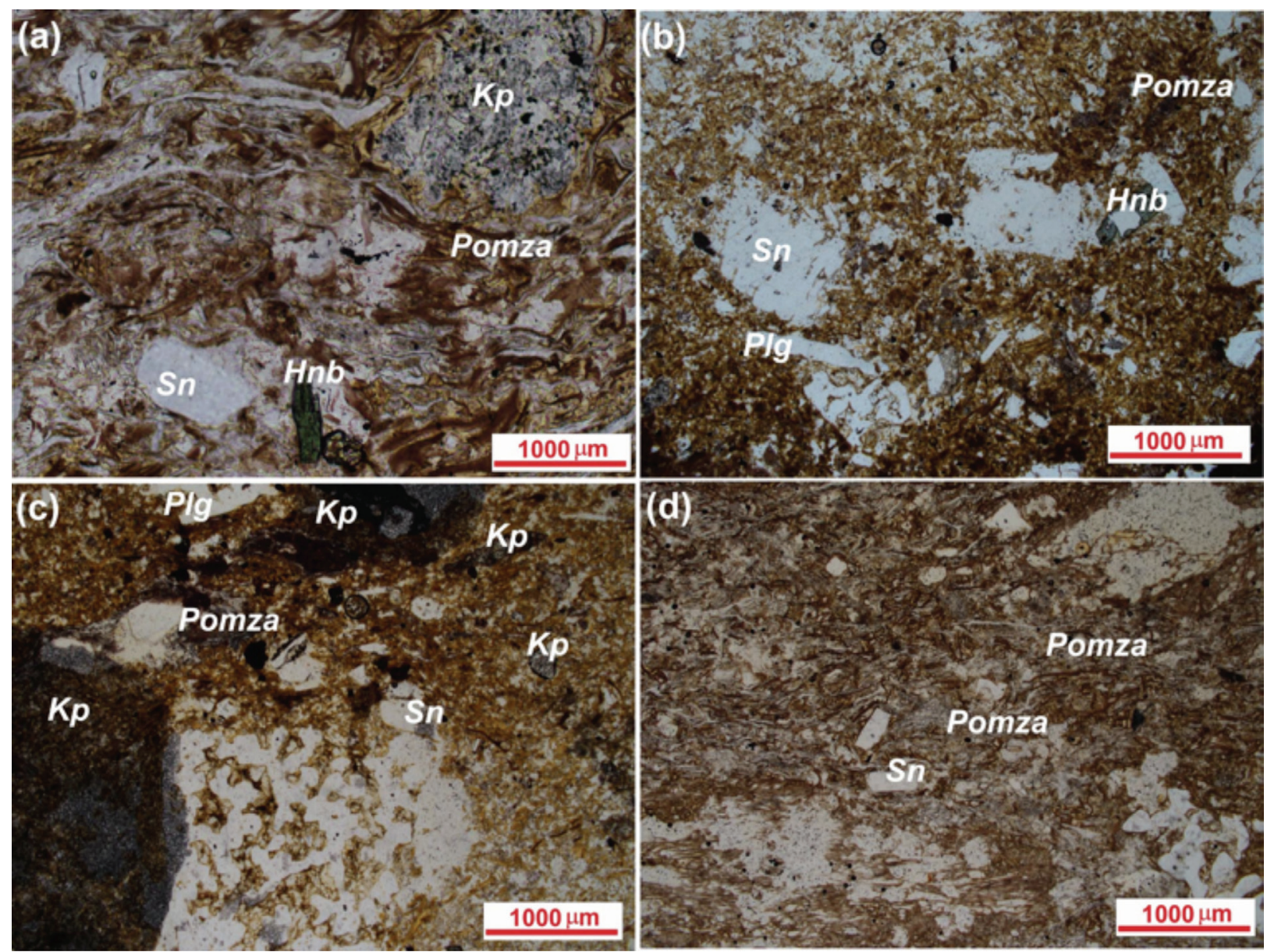

Şekil 4. Çalışma kapsamında incelenen ignimbiritlerin ince kesit fotoğrafları (Hnb: hornblend, Kp: kayaç parçası, Plg: plajiyoklaz, Sn: sanidin).

Figure 4. Thin section views of the studied ignimbrites (Hnb: hornblende, Kp:lithic fragment, Plg: plagioclase, Sn: sanidine).

İncelenen Ahlat ignimbiritlerinin kimyasal bileşimi Çizelge 2'de verilmiştir. Buna göre örnekler \% 60-70 oranında $\mathrm{SiO}_{2}$ içermektedir. $\% 15$ civarında bulunan $\mathrm{Al}_{2} \mathrm{O}_{3}$, ignimbiritlerin diğer önemli bileşenini oluşturmaktadır. Öte yandan örneklerde $\% 5$ oranında $\mathrm{Na}_{2} \mathrm{O}$ ve $\mathrm{K}_{2} \mathrm{O}$ belirlenmiştir. Toplam alkali silika diyagramına (Le Bas vd., 1986) göre Ahlat ignimbiritleri trakit ve riyolit grubundadır. 
Çizelge 2. İncelenen ignimbirit örneklerinin kimyasal bileşimleri.

Table 2. Chemical composition of the investigated ignimbrite specimens.

\begin{tabular}{|c|c|c|c|c|}
\hline \multicolumn{5}{|c|}{ Örnekler } \\
\hline$\%$ & N1 & $\mathbf{N} 2$ & N3 & N4 \\
\hline $\mathrm{SiO}_{2}$ & 66.25 & 66.80 & 72.43 & 66.04 \\
\hline $\mathrm{Al}_{2} \mathrm{O}_{3}$ & 16.03 & 15.53 & 12.44 & 16.24 \\
\hline $\mathrm{Fe}_{2} \mathrm{O}_{3}$ & 4.47 & 4.49 & 4.28 & 4.62 \\
\hline $\mathrm{MgO}$ & 0.21 & 0.20 & 0.04 & 0.23 \\
\hline $\mathrm{CaO}$ & 1.45 & 1.46 & 0.45 & 1.55 \\
\hline $\mathrm{Na}_{2} \mathrm{O}$ & 5.90 & 5.85 & 4.96 & 5.73 \\
\hline $\mathrm{K}_{2} \mathrm{O}$ & 5.11 & 5.11 & 5.10 & 5.01 \\
\hline $\mathrm{TiO}_{2}$ & 0.40 & 0.38 & 0.26 & 0.40 \\
\hline $\mathrm{P}_{2} \mathrm{O}_{5}$ & 0.06 & 0.07 & 0.01 & 0.06 \\
\hline $\mathrm{MnO}$ & 0.14 & 0.14 & 0.11 & 0.14 \\
\hline Toplam & 100 & 100 & 100 & 100 \\
\hline
\end{tabular}

\section{AHLAT İGNIMBİRITLERININ FIZIKO- MEKANIK ÖZELLIKLERİ}

Ahlat ignimbiritleri üzerinde yapılan deneysel çalışmalardan elde edilen sonuçlar Çizelge 3'te özetlenmiştir. Buna göre, N1, N2, N3 ve N4 kodlu ignimbiritlerin ortalama birim hacim ağırlıkları sırasıyla $15.13,15.77,16.82$ ve 14.85 $\mathrm{kN} / \mathrm{m}^{3}$ 'tür. $\mathrm{Bu}$ değerler, Ahlat ignimbiritlerinin çok düşük birim hacim ağırlığa sahip kaya grubunda (NBG, 1985) olduğunu göstermektedir. Öte yandan, incelenen örneklerin gözenekliliği çok yüksek olup, \% 20.35 ile \% 31.53 arasında değişmektedir. Örneklerin tek eksenli basınç dayanımları incelendiğinde, N1, N2 ve N4 nolu örneklerin dayanımları benzer olup, $12.10 \mathrm{MPa}$ ile $15.78 \mathrm{MPa}$ arasında değişmektedir. Ancak, sarıms1 gri renkli N3 nolu örnek grubunun dayanımı, iyi kaynaklaşma derecesine de bağlı olarak, daha yüksek olup, $28.92 \mathrm{MPa}$ olarak belirlenmiştir. Fakat, yine de tüm ignimbirit gruplar1 Deere ve Miller (1966) sinıflamasına göre düşük-çok düşük dayanımlı kaya grubuna girmektedirler. Doygun koşullardaki dayanım değerlerine bakıldığında ise, ignimbiritlerde kuru ve doygun koşullar arasında önemli bir dayanım değişiminin olmadığı görülmektedir. İncelenen ignimbiritlerde P-dalgası hızları da 1491 ile 2623 $\mathrm{m} / \mathrm{s}$ arasında değişmektedir. En yükssek P dalgası hız1 N3 grubu örneklerde iken, en düşük hız N4 nolu örnek grubuna aittir.

Çizelge 3. Ahlat ignimbiritlerinin (N1, N2, N3, N4) fiziko-mekanik özellikleri.

Table 3. Physico-mechanical properties of the Ahlat ignimbrites (N1, N2, N3, N4).

\begin{tabular}{lccccccccc}
\hline \multirow{2}{*}{ Parametre } & \multicolumn{3}{c}{ N1 } & \multicolumn{2}{c}{ N2 } & & \multicolumn{2}{c}{ N3 } & \multicolumn{2}{c}{ N4 } \\
\cline { 2 - 9 } & Ort & $\mathbf{n}$ & Ort & n & Ort & n & Ort & n \\
\hline Kuru Birim Hacim Ağıılık $\left(\mathrm{kN} / \mathrm{m}^{3}\right)$ & 15.13 & $(30)$ & 15.77 & $(21)$ & 16.82 & $(8)$ & 14.85 & $(26)$ \\
Doygun Birim Hacim Ağırlık $\left(\mathrm{kN} / \mathrm{m}^{3}\right)$ & 17.89 & $(7)$ & 18.60 & $(12)$ & 18.59 & $(7)$ & 18.00 & $(12)$ \\
Görünür gözeneklilik (\%) & 28.89 & $(11)$ & 27.40 & $(12)$ & 20.35 & $(6)$ & 31.53 & $(12)$ \\
Ă̆ırlıkça Su Emme (\%) & 18.68 & $(11)$ & 16.92 & $(12)$ & 12.03 & $(6)$ & 20.80 & $(12)$ \\
Tek Eksenli Basınç Dayanımı (MPa) & 15.78 & $(5)$ & 12.10 & $(3)$ & 28.92 & $(6)$ & 12.43 & $(6)$ \\
Tek Eksenli Basınç Dayanımı (MPa)* & 13.59 & $(10)$ & 12.17 & $(10)$ & 26.83 & $(3)$ & 12.31 & $(10)$ \\
P-dalga Hızı (m/sn) & 1709 & $(14)$ & 2378 & $(7)$ & 2623 & $(4)$ & 1491 & $(10)$ \\
P-dalga Hızı (m/sn)* & 1554 & $(6)$ & 2257 & $(7)$ & 2212 & $(4)$ & 1287 & $(7)$ \\
\hline
\end{tabular}

* Doygun koşul, n: Deney sayısı 
Akın, Dinçer, Özvan, Oyan, Tapan

\section{AHLAT İGNIMBIRITLERINIIN KILCAL SU EMME ÖZELLİKLERI}

Tarihi yapıları olumsuz yönde etkileyen en önemli unsurlardan bir tanesi sudur. Su tek başına veya diğer çevresel faktörlerle birlikte yapıtaşlarının mekanik özelliklerini olumsuz yönde etkilemekte ve bozunmayı hizlandirmaktadır (Cueto vd., 2009). Kilcal su emme, kayaların nem içeriğini artıran önemli unsurlardan biridir. Gözenekli bir ortam sıvı ile temas ettiğinde, kılcallık özelliğinden dolayı sıvıyı bünyesine alır. Yapıtaşının kılcal su emme özelliğine bağlı olarak su tabandan tavana doğru yükselir. Kayaların kılcal su emme özelliğinin bozunmayı artırdığı çeşitli bilimsel yayınlarda belirtilmektedir (Özdemir, 2002; Y1ld1z vd., 2010).

Ahlat ignimbiritlerinde, boy/çap oranı 1 olan örnekler üzerindeki k1lcal su emme deneylerinin yanı sıra, kılcal yükselim hızı ve davranışını gözlemlemek için boy/çap oranı 2/1 olan karot örnekleri üzerinde de suyun kılcal etki ile yükselimi izlenmiştir. $\mathrm{Bu}$ model deneye ait görüntüler Şekil 5'te gösterilmektedir. N2 ve N4 nolu ignimbirit örnekleri, hızlı bir kılcal yükselimle, ilk 25 dakikalık k1lcal su emme deneyi sonunda tamamen doygun hale gelmiştir. Aynı zaman diliminde (25 dk) N1 ve N3 nolu örneklerdeki tabandan itibaren k1lcal su yükselimi 9.27 ve 2.74 cm'dir. N3 nolu örneğin yüksek kaynaklaşma derecesi ve içerdiği kaya parçaları kılcal su yükselimini engellemiştir. 300 dakika sonunda tüm örnekler doygun hale gelmiş olsalar da, Şekil 5'te de görüleceği üzere, N3 nolu örneğin üst bölümündeki kaya parçası halen kuru durumdadır. Bu duruma göre, ignimbiritler içerisindeki farklı boşluk yapısına sahip olan çeşitli litik parçalar kılcal su emme davranışını kontrol etmektedir (Özvan vd., 2015).

Şekil 6-a'da ise ignimbiritlerin ortalama k1lcal su emme $\left(\mathrm{g} / \mathrm{m}^{2}\right)$ - karekök zaman (saniye) grafiği gösterilmiştir. Grafiklerin dik kısmının eğiminden hesaplanan kılcal su emme katsayıları (C), N1, N2, N3 ve N4 nolu örnekler için sırasıyla $476.81,685.71,187.32$ ve $821.88 \mathrm{gr} / \mathrm{m}^{2} \cdot \mathrm{sn}^{0.5}$ ' dir. N3 nolu örneğin k1lcal su emme katsayısı diğer üç örnek grubundan oldukça düşüktür. Snethlage (2005)'e göre, incelenen tüm ignimbirit örnekleri yüksek su emme kapasitesine sahip kaya grubuna girmektedir. İgnimbirit örneklerindeki zamana bağlı kılcal su yükselimini gösteren grafik Şekil 6-b'de sunulmaktadır. Grafikten de görüleceği üzere, N1, N2 ve N4 örneklerinde ilk 10 dakikalık dönemde hızlı bir kılcal yükselim gözlenirken, N3 nolu örnekte, litik malzemeler tarafindan kontrol edilen, tamamen farklı ve yavaş bir yükselim söz konusudur. 

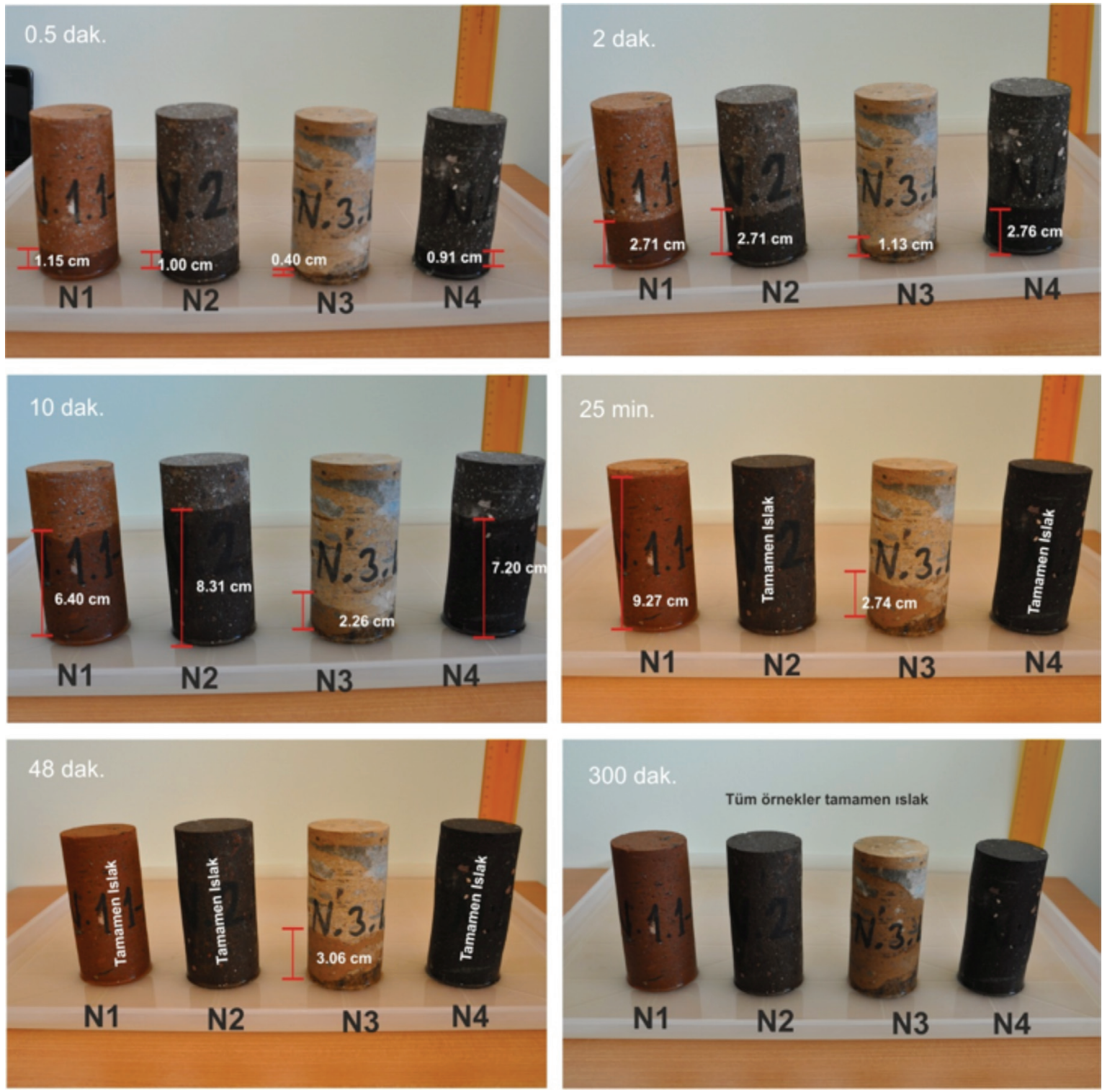

Şekil 5. ̇gnimbiritlerde kılcal su emme davranışına ait farklı zaman aralıklarında alınmış görüntüler.

Figure 5. Views of capillary water absorption behavior of ignimbrites taken at different time intervals. 

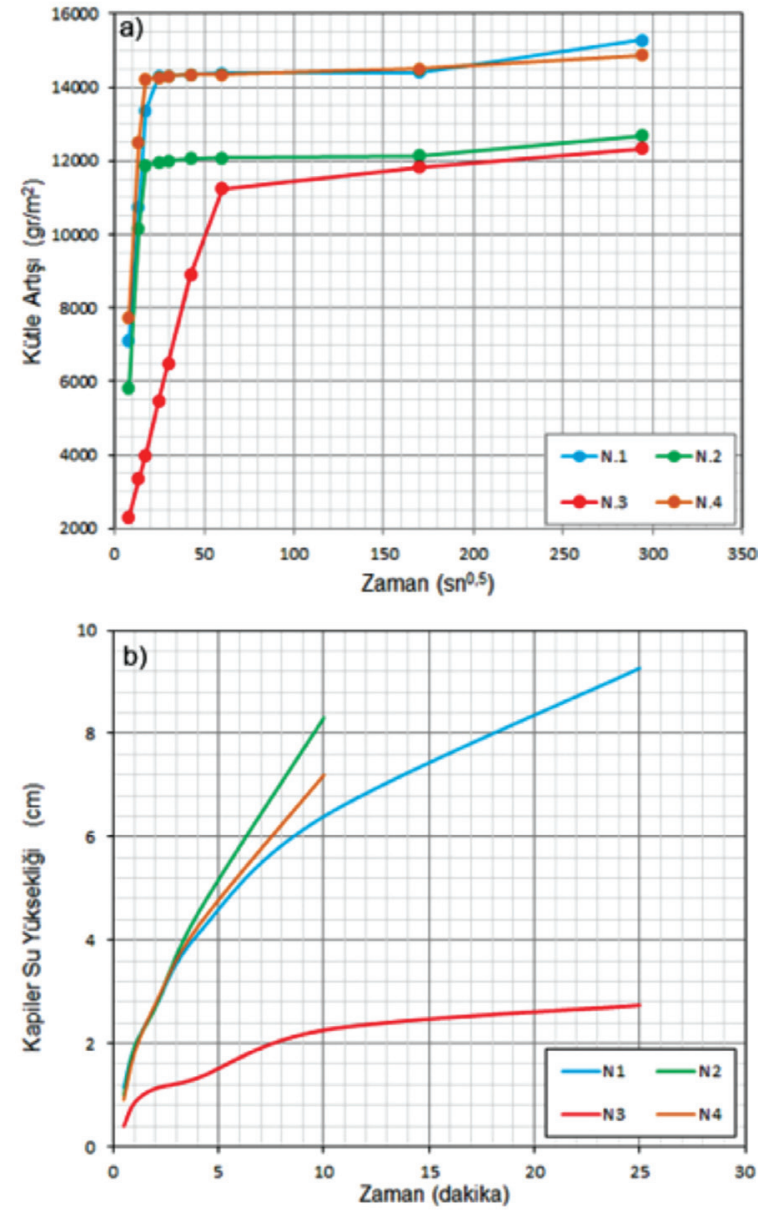

Şekil 6. İgnimbiritlerde zamana bağlı kılcal su emme grafikleri.

Figure 6. Capillary water absorption versus time graphs of the ignimbrites.

\section{AHLAT İGNIMBIRITTLERINDE GÖZENEK BOYUTLARI}

Ahlat ignimbiritlerindeki gözenek boyutları ve dağılımı, civa porozimetresi deneyleri ile ortaya konmuştur. İncelenen dört farklı ignimbirit seviyesine ait, kümülatif gözenek hacmine karşılık gözenek çapını gösteren grafikler Şekil 7'de gösterilmiştir. Eğrilerde, diğer örnek gruplarından farklı olarak N3 nolu sarımsı gri ignimbiritlerin toplam boşluk hacminin 0.085 $\mathrm{cm}^{3} / \mathrm{g}$ olduğu görülürken, $\mathrm{N} 1, \mathrm{~N} 2$ ve $\mathrm{N} 4$ nolu örnek gruplarında toplam boşluk hacmi 0.148 ile $0.189 \mathrm{~cm}^{3} / \mathrm{g}$ arasında değişmektedir. Tüm örnek gruplarında gözenek çapı 0.004 ile $200 \mathrm{~mm}$ arasında değişmekle birlikte bazı gözenek çap1 değerlerinde ani sıçramalar dikkati çekmektedir. Örneğin N3 nolu ignimbiritlerde bu ani artışlar 5 ile $7 \mathrm{~mm}$ arasındayken, diğer örneklerde 20 ile $50 \mathrm{~mm}$ arasında gözlenmektedir. Gözenek boyutlarıyla ilgili bu eğrilerdeki ani yükselimler baskın gözenek çapını işaret etmektedir (Tuğrul, 2004). Bu sonuca göre, N1, N2 ve N4 nolu ignimbirit örneklerinin gözenek çapları, N3 nolu örneğe göre daha büyüktür (Özvan vd., 2015).

\section{AHLAT SELÇUKLU MEZAR TAŞLARINDA BOZUNMA}

İgnimbiritlerdeki mühendislik özelliklerini kontrol eden en önemli faktörler kaynaklaşma derecesi ve litik malzeme içeriğidir. Öte yandan, ignimbiritlerin yüksek kılcal su emme özelliği, yapıtaşı olarak kullanılanların duraylılıkları üzerinde olumsuz etkiler oluşturabilmektedir. Benavente vd. (2001), gözenek boyutu ve gözenekli ortamdaki sıvının hareketine neden olan kuvvetleri dikkate alarak üç farklı gözenek sınıfı önermiştir. Buna göre, gözenek çapı 2500 mm'den büyük olan ve gözeneklerdeki sıv1 hareketinin yerçekimi kuvvetleri tarafindan kontrol edildiği gözeneklilik, makro gözeneklilik olarak tanımlanmıştır. Gözenek çapının 0.1 ile $2500 \mathrm{~mm}$ arasında değişmesi durumunda mezo gözeneklilikten söz edilir ve sıvı hareketi k1lcal kuvvetler ile sağlanır. Gözenek çap1 0.1 mm'nin altında ise ortam mikro gözeneklidir ve adsorpsiyon kuvvetleri sıvı hareketini yönlendirir. $\mathrm{Bu}$ sinıflamaya göre, civa porozimetresi 
deney sonuçları dikkate alındığında, Ahlat ignimbiritleri mezo ve mikro gözenekli olarak sinıflandırılabilirler. $\mathrm{Bu}$ nedenledir ki, Ahlat ignimbiritleri içerisindeki sıv1 hareketi k1lcal kuvvetler yardımıyla gerçekleşir. İncelenen N3 nolu ignimbirit örneği daha düşük baskın gözenek çapı değerleri (5-7 mm) sunmakla birlikte, kılcal su emme deneylerinde diğer örneklere oranla düşük su emme özelliği göstermiştir. Her ne kadar bu durum çelişsili görünmekle birlikte, daha önceki bölümlerde de belirtildiği üzere, N3 nolu örneğin içerisindeki geçirimsiz bariyer oluşturan litik malzemelerin bu sonuca neden olduğu düşünülmektedir (Özvan vd., 2015). olan mezar taşlarının orta bölgeleri kılcal bölge içerisinde kalmaktadır ve bu zonda tuz kristallenmesi daha aktiftir. Benavente vd. (2001) tarafından da belirtildiği üzere, kılcal bölgedeki tuz kristallenmesi doygun bölgeye oranla daha yüksektir. Bu nedenle bozunma mezar taşlarının orta bölümlerinde daha etkili olmaktadır. Selçuklu mezarlığında yapılan arazi gözlemleri, mezar taşlarının belirli bir yükseklikte kırıldığını göstermektedir. 941 adet kırık mezar taşı üzerinde yapılan ölçümlerde kırılma yüksekliğinin yerden itibaren 10 ile $70 \mathrm{~cm}$ arasında değiştiğibelirlenmiş olup, bu mesafe ortalama kilcal su emme yüksekliğine karşıllk gelmektedir (Şekil 8-a,b).

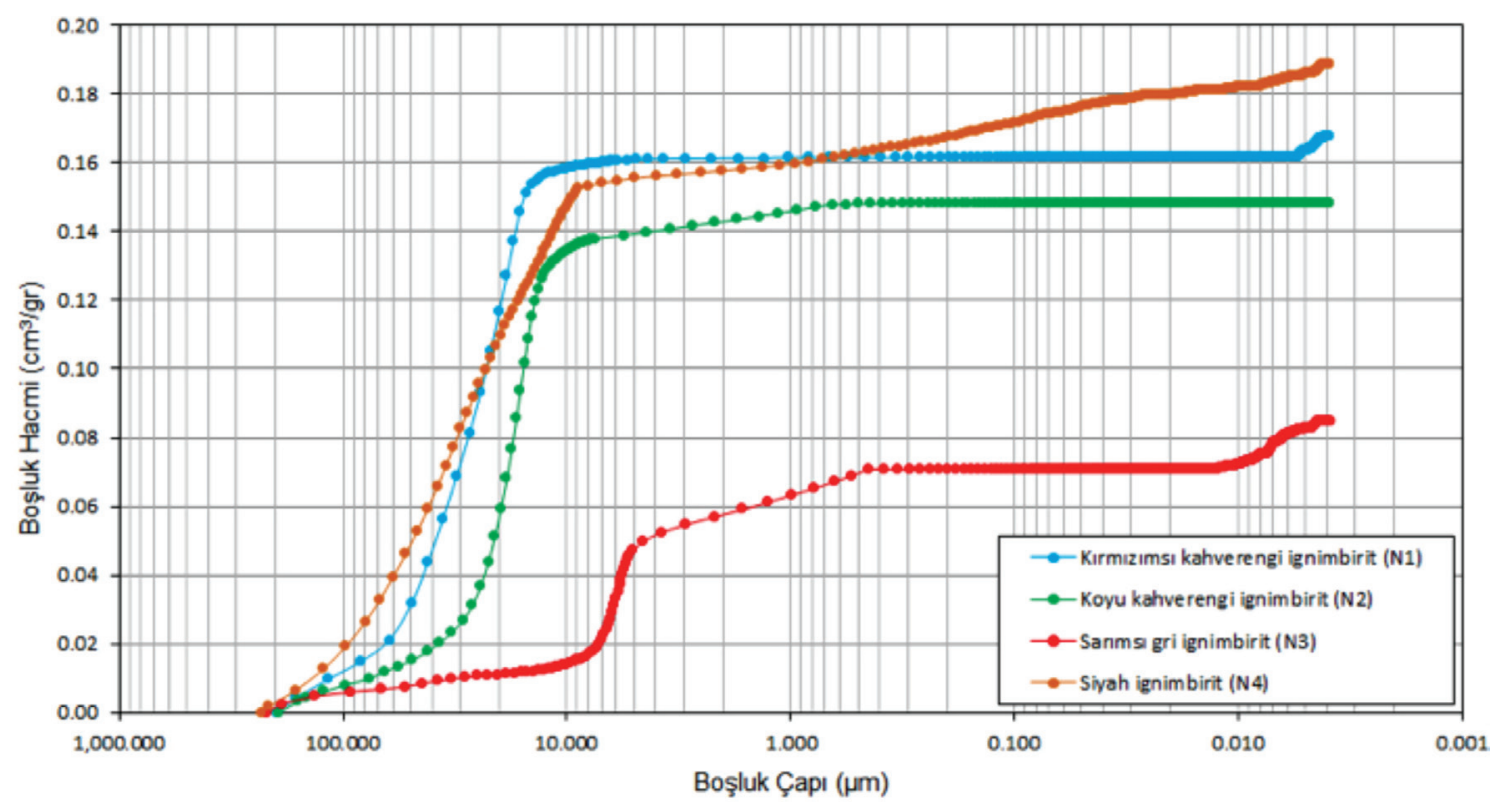

Şekil 7. İncelenen ignimbirit örneklerinin gözenek hacmi-gözenek çapı eğrileri.

Figure 7. Pore volume versus pore diameter graphs of the investigated ignimbrites.

Ahlat ignimbiritlerinin kullanıldı $\breve{g} 1$ tarihi Ahlat Selçuklu Mezar Taşları'ndaki fiziksel bozunmanın en önemli sebebinin, yüksek kılcal su emmeden kaynaklandığını söylemek mümkündür. Yaklaşı 1-2 m yükseklikte
Tuzlu suyun mezar taşlarının orta seviyelerine kadar yükselebileceği laboratuvarda yapılan model deneylerle de desteklenmiştir (Şekil 8-c). Model deneylerde üç ay sonunda, kılcal su emme ile birlikte tuzlu suyun örneklerin orta 
Akın, Dinçer, Özvan, Oyan, Tapan

seviyelerinden daha yukarılara kadar taşındığ gözlenmiştir. Örneklerin mezar taşlarına oranla daha küçük olması sebebiyle tuzlu su, kılcallığın da etkisiyle örneklerin en üst seviyelerine kadar ulaşabilmiştir (Şekil 8-c). Kırık mezar taşlarının ortalama yüksekliği $60-70 \mathrm{~cm}$ civarında olup, bu değerler mezar taşlarının orta-alt bölgelerine karşılık gelmektedir. Bu nedenle, Ahlat Selçuklu Mezar Taşları'nda bozunmanın en önemli nedeni kılcal su emme ile birlikte mezar taşı içerisinde yukarı taşınan tuzlu sudur. Bilindiği üzere bölge tuzlu-sodalı su özelliğine sahip olan Van Gölü kıyısında bulunmaktadır. Mezarlıktaki çözünebilen tuzların da bölgedeki yüksek alkali volkanik kayaçlardan ve/veya ölü bedenlerin çürümesinden (Dent, 2002) kaynaklandığ 1 düşünülmektedir.

Ahlat Selçuklu Mezarlığı'ndaki mezar taşlarının yöneliminin, bozunma üzerinde önemli bir rolü olmadığı arazi gözlemleri ile ortaya konmuştur. Yapılan incelemelerde mezar taşlarının her iki yönünde de bozunmanın izleri gözlenmiştir. Bunun yanı sıra, nemlilik bozunmayı kontrol eden en önemli çevresel faktördür. Mezar taşlarının alt ve orta kesimleri k1lcal su emmeye ve tuz kristallenmesine bağlı olarak çok daha fazla bozunmuş durumdadır.
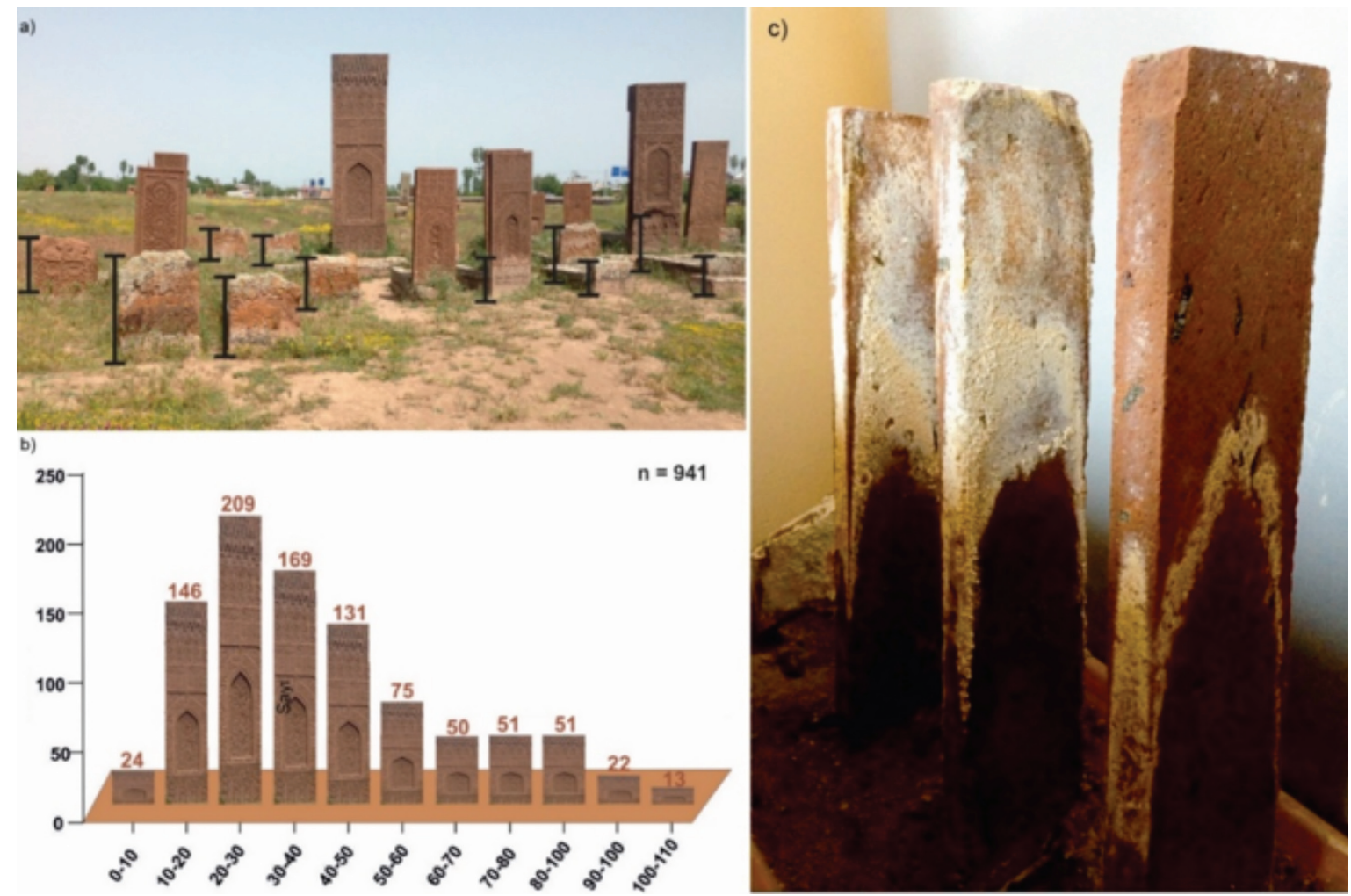

Şekil 8. Ahlat Selçuklu Mezar Taşları'nda kırılma boyları (a, b), ignimbiritlerdeki kılcal su emmeye bağlı tuz yükseliminin laboratuvarda modellenmesi (c).

Figure 8. Broken length of the Ahlat Seljuk Tombstones ( $a$, b), laboratory modelling of the rise of salt in the ignimbrites due to capillary water absorption. 


\section{SONUÇLAR}

İgnimbiritlerin kullanıldığı Ahlat Selçuklu Mezar Taşları'nın bozunma mekanizmasının irdelendiği bu çalışma sonucunda, yüksek kılcal su emme özelliğinin mezar taşlarının bozunmasındaki en önemli etken olduğu belirlenmiştir. Mezar taşlarının toprağa gömülü olan kısımlarından kılcal su emme ile birlikte kaya malzemesi içerisinde yükselen su, toprak kaynaklı tuzu da bünyesine alarak mezar taşlarının orta bölümlerine kadar taşımakta ve bu bölgede tuz birikimlerine neden olmaktadır. İgnimbiritlerin gözeneklerindeki tuzun çevrimsel olarak kristallenmesi ile birlikte mezar taşları bozunarak orta-alt bölgelerinden kırılmışlardır.

Litik malzeme içeriği ve kaynaklaşma derecesi ignimbiritlerin mühendislik özelliklerini kontrol etmekle beraber, özellikle ignimbiritler içerisindeki pomza ve diğer kayaç parçalarının oluşturduğu litik malzemeler, kılcal su emme davranışı üzerinde de etkili olabilmektedir. Düşük geçirgenliğe sahip litik malzemeler geçirimsiz bir bariyer gibi davranarak ignimbiritlerde k1lcal su yükselimini engellemektedir.

\section{TEŞEKKÜR}

Bu çalışma, 2012-MİM-B011 numaralı proje ile Yüzüncü Yıl Üniversitesi Bilimsel Araştırma Projeleri Başkanlığı'nca desteklenmiştir. Yazarlar, arazi çalışmaları sırasındaki yardımlarından dolayı Prof. Dr. Recai Karahan ve ekibine teşekkür ederler.

\section{KAYNAKLAR}

Akbaş, B., Akdeniz, N., Aksay, A., Altun, İ., Balcı, V., Bilginer, E., Bilgiç, T., Duru, M., Ercan, T.,
Gedik, İ., Günay, Y., Güven, İ.H., Hakyemez, H. Y., Konak, N., Papak, İ., Pehlivan, Ş., Sevin, M., Şenel, M., Tarhan, N.,Turhan, N., Türkecan, A., Ulu, Ü., Uğuz, M.F., Yurtsever, A. ve diğerleri, 2015. Türkiye Jeoloji Haritası, Maden Tetkik ve Arama Genel Müdürlüğü Yayını, Ankara, Türkiye.

Akın, M., Özsan, A., 2011. Evaluation of the long-term durability of yellow travertine using accelerated weathering tests. Bulletin of Engineering Geology and the Environment, 70 (1), 101-114.

Arino, X., Ortega-Calvo, J. J., Gomez-Bolea, A., Saiz-Jimenez, C., 1995. Lichen colonization of the Roman pavement at Baelo Claudia (Cadiz, Spain): biodeterioration vs. bioprotection. Science of the Total Environment, 167, 353-363.

Aydar, E., Gourgaud, A., Ulusoy, I., Digonnet, F., Labazuy, P., Sen, E., Bayhan, H., Kurttas, T., Tolluoğlu, A. U., 2003. Morphological analysis of active Mount Nemrut stratovolcano, eastern Turkey: evidences and possible impact areas of future eruption. Journal of Volcanology and Geothermal Research, 123, 301-312.

Benavente, D., García Del Cura, M. A., Bernabéu, A., Ordóñez, S., 2001. Quantification of salt weathering in porous stones using an experimental continuous partial immersion method. Engineering Geology, 59, 313-325.

Cardenes, V., Mateos, F. J., Fernandez-Lorenzo, S., 2014. Analysis of the correlations between freeze-thaw and salt crystallization tests. Environmental Earth Sciences, 71, 1123-1134.

Carter, N., Viles, H., 2005. Bioprotection explored: the story of a little known earth surface process. Geomorphology, 67, 273-281.

Cueto, N., Benavente, D., Martínez-Martínez, J., García-del-Cura, M. A., 2009. Rock fabric, 
pore geometry and mineralogy effects on water transport in fractured dolostones. Engineering Geology, 107, 1-15.

Deere, D. U., Miller, R. P., 1966. Engineering classification and index properties of intact rock. Technical Report No: AFNL-TR-65-116, Kirtland Air Force Base Weapons Laboratory, New Mexico.

Dent, B. B., 2002. The hydrogeological context of cementery operations and planning in Australia. PhD Thesis, vol. 1., The University of Technology, Sydney, 453 p.

Elmastaş, N., 2001. Ahlat yöresinin turizm potansiyeli. Marmara Coğrafya Dergisi, 3 (1), 153-182.

Garcia-Valles, M., Gimeno-Torrente, D., MartínezManent, S., Fernandez-Turiel, J. L., 2003. Medieval stained glass in a Mediterranean climate: typology, weathering and glass decay, and associated bio-mineralization processes and products. American Mineralogist, 88, 19962006.

Garty, J., 1992. The postfire recovery of rockinhabiting algae, microfungi and lichens. Canadian Journal of Botany, 70, 301-312.

ISRM, 2007. The Complete ISRM Suggested Methods for Rock Characterization, Testing and Monitoring: 1974-2006. In: Ulusay, R., Hudson, J. A., editors, $628 \mathrm{p}$.

Karamağaralı, B., 1992. Ahlat Mezar Taşları. Türkiye Cumhuriyeti Kültür ve Turizm Bakanlığı, Sanat Tarihi Yayınları.

Karaoğlu, Ö., Özdemir, Y., Tolluoğlu, A. Ü., Karabıyıkoğlu, M., Köse, O., Froger, J. L., 2005. Stratigraphy of the volcanic products around Nemrut Caldera: Implications for reconstruction of the caldera formation. Turkish Journal of Earth Science, 14, 123-143.
Keskin, M., 2007. Eastern Anatolia: A hot spot in a collision zone without a mantle plume. GSA Special Paper, 430, 695-722.

Korkanç, M., 2013. Deterioration of different stones used in historical buildings within Niğde province, Cappadocia. Construction and Building Materials, 48, 789-803.

Le Bas, M. J., Le Maitre, R. W., Streckeisen, A., Zanettin, B., 1986. A chemical classification of volcanic rocks based on the total alkali-silica diagram. Journal of Petrology, 27, 745-750.

Lisci, M., Monte, M., Pacini, E., 2003. Lichens and higher plants on stone: a review. International Biodeterioration and Biodegradation, 51, 1-17.

Mottershead, D., Gorbushina, A., Lucas, G., Wright, J., 2003. The influence of marine salts, aspect and microbes in the weathering of sandstone in two historic structures. Building and Environment, 38, 1193-1204.

NBG, 1985. Norwegian Rock Mechanics Group: Handbook in engineering geology - rock. Tapir, Trondheim, Norway.

Öner, F., Türkmen, S., Özbek, A., Karakaya, T., 2006. Engineering properties of Hinıs Ignimbrites (Erzurum, Turkey) and their usability as a building stone. Environmental Geology, 50, 275-284.

Özdemir, A., 2002. Capillary water absorption potentials of some building materials. Geological Engineering, 26, 19-32.

Özdemir, Y., Karaoğlu, Ö., Tolluoğlu, A. Ü., Güleç, N., 2006. Volcanostratigraphy and petrogenesis of the Nemrut stratovolcano (East Anatolia High Plateau): The most recent post-collisional volcanism in Turkey. Chemical Geology, 226, 189-211. 
Özvan, A., Dinçer, İ., Akın, M., Oyan, V., Tapan, M., 2015. Experimental studies on ignimbrite and the effect of lichens and capillarity on the deterioration of Seljuk Gravestones. Engineering Geology, 185, 81-95.

Prikryl, R., Lokajicek, T., Svobodova, J., Weishauptova, Z., 2003. Experimental weathering of marlstone from Predni Kopanina (Czech Republic)—historical building stone of Prague. Building and Environment, 38 (9-10), 1163-1171.

Seaward, M., 2001. The role of lichens in the biodeterioration of ancient monuments with particular reference to central Italy. International Biodeterioration and Biodegradation, 48, 202208.

Siegesmund, S., Weiss, T., Vollbrecht, A., 2002. Natural Stone, Weathering Phenomena, Conservation Strategies and Case Studies. Special Publication, The Geology Society of London.

Snethlage, R., 2005. Leitfaden zur Steinkonservierung. Fraunhofer IRB Verlag, Stuttgart.

Topal, T., Doyuran, V., 1997. Engineering geological properties and durability assessment of the Cappadocia Tuff. Engineering Geology, 47(1-2), 175-187.
Topal, T., Sözmen, B., 2003. Deterioration mechanisms of tuffs in Midas monument. Engineering Geology, 68, 201-223.

Török, A., 2006. Hungarian travertine: weathering forms and durability. In: Fort R, Alvarez de Buego M, Gomez-Heras M, VazquezCalvo C (eds) Heritage weathering and conservation, vol I. Taylor \& Francis/Balkema, London, 199-204.

TS 699, 2009. Doğal yapı taşları, muayene ve deney metotları. Türk Standartları Enstitüsü, Ankara.

Tuğrul, A., 2004. The effect of weathering on pore geometry and compressive strength of selected rock types from Turkey. Engineering Geology, $75,215-227$.

UNE-EN, 1925, 1999. Natural stone test method. Determination of water absorption coefficient by capillarity.

www.mgm.gov.tr, 2016. Meteoroloji Genel Müdürlüğü, Erişim tarihi: 27.05.2016

Yıldız, M., Özşahin, Y. E., Soğancı, A. S., 2010. Deteriorations on Historical Buildings due to capillarity; Aksaray Sultanhanı Caravansary Model BALWOIS. Ohrid, Republic of Macedonia. 
